\title{
Evaluation Model of the Production System Effectiveness
}

\author{
Ahmed Bounit $^{\mathrm{a},{ }^{*}}$, Elhassan Irhirane $^{\mathrm{a}}$, Badr Dakkak ${ }^{\mathrm{a}}$, Abdelatif Rajji $^{\mathrm{b}}$, and Abaida Abdellah ${ }^{\mathrm{c}}$ \\ ${ }^{a}$ Department of Industrial and Logistical Engineering, National School of Applied Sciences, Cadi-Ayyad University, Marrakech, 40000, Morocco \\ ${ }^{b}$ Laboratory of Environment, Beni Mellal, 23000, Morocco \\ ${ }^{c}$ Laboratory of Applied Research and Studies in Economics, Settat, 26004, Morocco
}

\begin{abstract}
The valuation of a production system's effectiveness requires a more appropriate decision-making indicator. The absence of this indicator constitutes a disability to give the managers a method to attain performance at the level of their services. In this article, we propose a model based on fuzzy logic that assess system effectiveness of manufacturing production. As a result, this model guides the operational decision-makers (maintenance, production, quality) to make the best decision and to have a more global vision of the production system's performance. A case study was done within an industrial firm to test the offered model. Results show that the model is more realistic, robust and has better stocks compared to the classical method.
\end{abstract}

Keywords: effectiveness; indicator of performance; fuzzy logic; system of production

(Submitted on July 12, 2019; Revised on August 19, 2019; Accepted on August 30, 2019)

(C) 2019 Totem Publisher, Inc. All rights reserved.

\section{Introduction}

Many companies are undergoing major reconstruction and profound changes. They face a ruthless world of competition that continuously aims to improve quality, product prices, motivation, safety of goods and people, and the respect of the work environment. As a result, most of them have production systems that are increasingly complex and sophisticated and subject to losses from multiple and varied origins that are both untimely failures due to the unavailability of the equipment tool due to clean and induced shutdowns, loss of performance due to slowdowns and differences in speed and lower quality generated. These losses of efficiency lead to a decrease in yield and increase the indirect costs and costs return.

As experience has evolved, the evaluation of the manufacturing production system efficiency through the use of indicators has a very important impact on reducing costs and improving the quality. Because of the increasing complexity of industrial systems and the importance attached to their ability to function properly and in a continuous manner, the need to evaluate their overall performance has been the subject of much work [1-4]. They are limited to the measurement of performance indicators and no one alluded to cognitive analysis based on the capitalization of knowledge to help the decision-maker. Hence, it is necessary to focus on fuzzy logic modeling of the relevant indicators. Then, the assessment will start with a view to achieve a steering system as one multi-criteria decision support system, which is part of an interactive approach with the decision-maker.

The results and simulations will be detailed in the next parts.

\section{Performance Indicators of Production Systems}

Nowadays, companies are constantly confronted with competition that continuously aims to improve the quality and prices of products as well as production times. As a result, most of them have production systems that are both more efficient and more fragile. This imposes the need of performance indicators to monitor the performance of the maintenance program and seeks to improve the performance of production equipment through concrete involvement in everyday life of all stakeholders.

\footnotetext{
* Corresponding author.

E-mail address: ahmedguelmim@gmail.com
} 
The TRS breaks down according to the NF E 60-182 standard. The state times are measured. They represent the activity (or inactivity) of the means of production and are the source of the components of TRS [5]. Most of them are defined in great detail in this standard.

Figure 1 below summarizes this funnel structure from total time to useful time.

\begin{tabular}{|c|c|c|c|c|c|}
\hline \multicolumn{6}{|c|}{$\pi$ = Total Time } \\
\hline \multicolumn{5}{|c|}{ OT = Opening Time } & Closure \\
\hline \multicolumn{4}{|c|}{ TR = Required Time } & Change-over & \\
\hline \multicolumn{3}{|c|}{ OT = Operating Time } & $\begin{array}{l}\text { Breakdown, } \\
\text { micro-stops }\end{array}$ & & \\
\hline \multicolumn{2}{|l|}{ NT $=$ Net Time } & $\begin{array}{l}\text { Gap } \\
\text { pace }\end{array}$ & & & \\
\hline UT = Useful Time & $\begin{array}{c}\text { No- } \\
\text { Quality }\end{array}$ & & & & \\
\hline
\end{tabular}

Figure 1. Decomposition of time according to AFNOR

Total time (TT): reference period chosen for time analysis.

For a day, the total time is 24 hours; for a week, the total time is 168 hours; for one year, the total time is 365 days $\times 24$ hours, i.e. 8760 hours, etc.

Opening Time (OT): part of the total time that corresponds to the amplitude of the working hours of the means of production and includes the disengagement times of the means of production (under load, modification, test, pause).

Required Time (RT): time during which the means of production should have worked. This is the desired production time given the scheduled shutdowns. The required time is obtained by deducting from the opening time programmed downtime (cleaning, training, meeting, preventive maintenance, etc.).

Not Required Time: time during which the user of the entity does not require the entity to be able to perform a required function.

Operating Time (OT): time during which the means of production actually worked. It is obtained by deducting the required time from the unplanned downtimes (outages, hazards).

Net Time (NT): time during which the means of production would have produced good and bad parts while respecting the reference cycle time.

Useful Time (UT): time corresponding to the unmeasurable time obtained by multiplying the number of good parts by the reference cycle time or by dividing the number of good parts by the rate.

\subsubsection{Availability Rate (AR)}

This rate measures the performance of the main functions associated with the transformation process. It integrates the required time $(R T)$ and the operating time $(O T)$. The formula used to calculate this indicator is:

$$
A R=\frac{\text { Operating Time }}{\text { Required Time }}=\frac{O T}{R T}
$$

\subsubsection{Performance Rate $(P R)$}

This indicator takes stock of the losses due to a non-optimal operation. In other words, it measures the performance of the production manager. The formula used is the following:

$$
P R=\frac{\text { Net operating time }}{\text { Raw operating time }}
$$




\subsubsection{Quality Rate $(Q R)$}

This is the ratio of the number of good parts on the number of pieces realized. In other words, it is the ratio between the useful time and the net time. The formula of the calculation of this indicator is as follows:

$$
Q R=\frac{\text { Number of good pieces }}{\text { Number of pieces made }}
$$

\section{The Model}

Figure 2 describes the structure of the behavior of our system. The first step is to recover the measurement of the main indicators AR, PR, QR of origin of loss of performance, which are often reduced to lost time and thus, generate lost costs. They were classified into tree families, that is to say, without worrying about the functions (production, maintenance, quality) responsible or victims of these losses. In the case of a deviation, the piloting process is continued to detect the possible problem or malfunction. In the case of non-deviation, the piloting process resorts to the initial state.

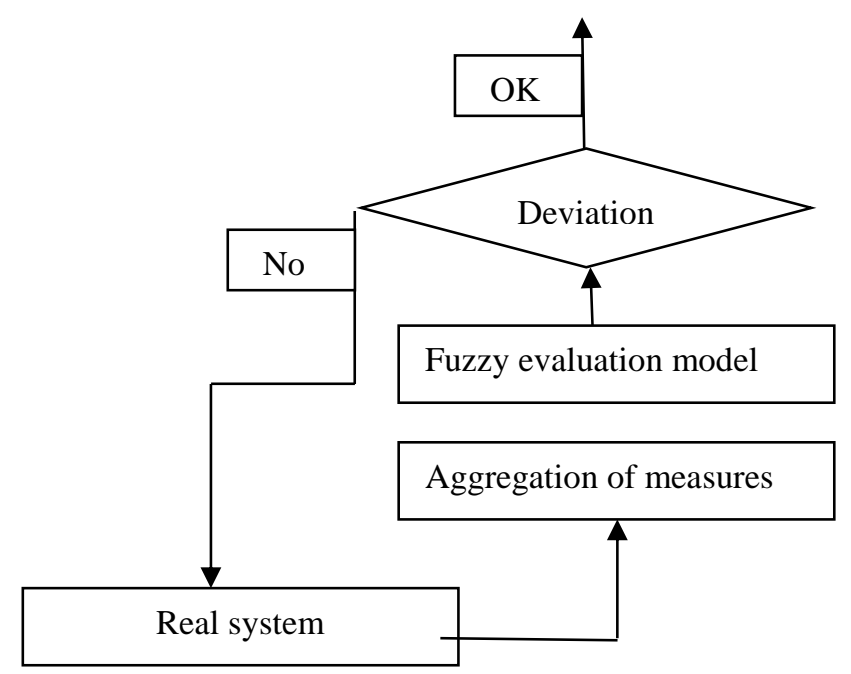

Figure 2. General scheme for the behavior of the system

\section{Proposed Approach: Fuzzy Logic Adapted to Indicators}

The proposed model exploits the dynamics of three components (quality ratio, performance rate and availability rate) to assess the efficiency of production systems and to take a global view of the situation and guide operational decision-making. In what follows we present the theory of fuzzy sets and propose the first evaluation model of the production system effectiveness system by the adaptation of the fuzzy modeling indicators.

\section{Method to Evaluate the Efficiency of the Production System by Fuzzy Logic}

\subsection{Introduction on Logic Fuzzy}

At the present time, fuzzy logic arouses a general interest on the part of all those who feel the need to formalize empirical methods, to generalize natural modes of reasoning, to automate decision-making in their field, or to construct artificial systems performing the same functions. Tasks are usually supported by humans [6].

Nowadays, fuzzy logic as a tool of formalization and analysis is used in many fields, including the modeling of a complex system, the recognition of forms, image analysis, the assistance to a decision, etc. Compared to other advanced computational techniques, fuzzy logic makes it possible to process both digital and linguistic data, and to formalize and analyze human qualitative knowledge. It is able to provide fast, robust and interpretable solutions. These advantages are particularly interesting for solving industrial problems often related to empiricism [7].

Let us insist here that fuzzy logic is the only framework in which uncertainties "that cannot be handled by statistical models or methods" and inaccuracies "that cannot be treated by statistical models" can be treated and also authorize the 
treatment of certain incompleteness. It is also the only framework in which digital knowledge symbolically expressed by natural language skills can be processed [6].

\subsection{Useful Definitions}

Fuzzy sets: the notation of fuzzy sets was introduced for the first time by [8] to mathematically represent the inaccuracy of certain classes of objects. A fuzzy set is a set of values that belong to a certain class with some certainty.

Operators of fuzzy logic: the operators make it possible to combine several propositions of the premise, that is to say to propose calculations on degrees of belonging to form the degree of truth. As with classical logic, we can define AND, OR, and NOT operators. The fuzzy logical operators only make the generalization of classical logic. The AND operator of the classical logic is well respected: 0 AND 1 gives well 0 . The OR operator of the classical logic is well respected: 0 OR 1 gives well 1. The operator negation of the classical logic is well respected: NO (0) gives well 1 and NO (1) gives well 0 [7].

Fuzzy variables: Fuzzy logic is based on fuzzy variables called linguistic variables, where linguistic values are the universe of the $U$ discourse and each linguistic value constitutes a fuzzy set of the universe of the discourse.

The discourse universe: range of variation of the linguistic variable

Linguistic values: linguistic translation of the various states of the linguistic variable in the fuzzy class or sub-set (strong, medium, weak $\cdots$ ). Each state is represented by a membership function.

The membership functions: instead of belonging to the "true" set or the "false" set of the traditional binary logic, the fuzzy logic admits degrees of belonging to a given set. The degree of membership of a fuzzy set is materialized by a number between 0 and 1 . factor".

A precise value of the membership function linked to a value of the variable is noted $\mu$ and called the "membership

Règles floues: a fuzzy rule is of the form "If I encounter this situation, then I draw such a conclusion". The situation, called premise or antecedent of the rule, is defined by a combination of relations of the form $\mathrm{x}$ for each of the components of the input vector. The conclusion of the rule part is called the consequence or the conclusion.

The rules are of two types:

- Mamdani is a fuzzy rule of type Mamdani, whose conclusion is a fuzzy set.

- Takagi-Sugeno from the Sugeno model where the conclusion of the rule is clear.

\subsection{Fuzzy Controller}

The fuzzy controller constitutes four main blocks: knowledge base, inference system, the interface of fuzzification and defuzzification. The knowledge base constitutes a database and a rules base. The database contains facts of the form " $x$ is A" linguistic variables of input and the output of the fuzzy controller. The base of the rules contains propositions of the form "if $\mathrm{x} 1$ is $\mathrm{A} 1$ and $\mathrm{x} 2$ is $\mathrm{A} 2$, then $\mathrm{y}$ is $\mathrm{B}$ ". The inference system is able to reason from information in the knowledge base and makes deductions. Figure 3 presents a general structure of the fuzzy controller:

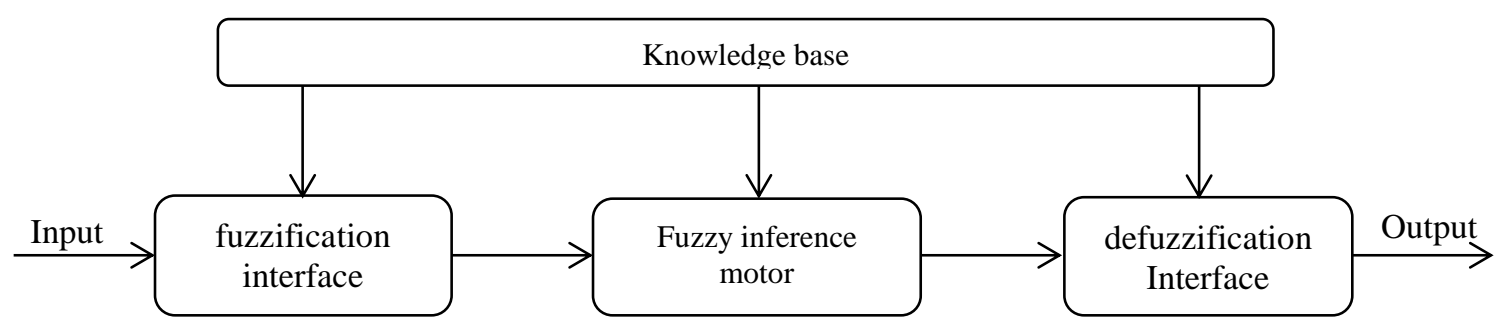

Figure 3. General scheme of a fuzzy controller

Generally, a fuzzy controller passes the following steps 
- Choice of the fuzzification strategy

- Establishment of the rule base

- Choice of the inference method

- Choice of the defuzzification strategy

\subsubsection{Fuzzification}

The step of fuzzification consists in transforming numerical greatness into linguistic variables for an inference treatment. So, each input and output variable has associated sets characterizing the linguistic terms taken by its variables. These terms will be used to write the inference rules. The choice of the membership functions form is arbitrary. There are several forms of the membership function whose triangular form is the most used [6] and [9]. The fuzzification passes by the steps represented in Figure 4:

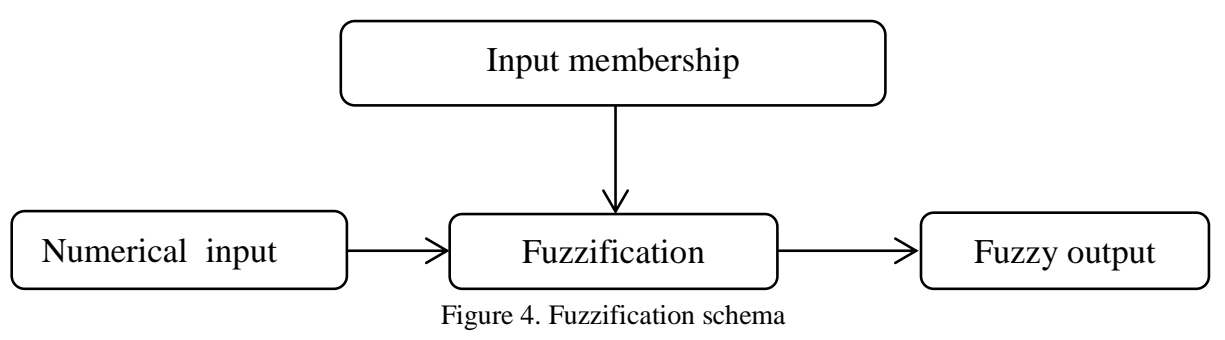

\subsubsection{Rule Base}

Fuzzy logic aims to exploit human reasoning in the sense of modeling concrete situations. Reaching this objective fuzzy logic is based on the notion of basic rules. A fuzzy rules base is a collection of rules that allows linked fuzzy input and output variables. The rules take the following form:

$$
\text { If } X \text { is } A \text {, and } Y \text { is } B \text {, then } Z \text { is } C
$$

Where $X$ and $Y$ are the fuzzy input system, $Z$ is the fuzzy output system, and $A, B$ and $C$ are the linguistic terms represented by fuzzy sets.

\subsubsection{Fuzzy Inference}

Fuzzy inference is used to calculate the fuzzy set associated with the command, and it is done by fuzzy inference operations and rule aggregation. It enters the premise part that constitutes the base of rules. The premise is a set of conditions linked together by form conjunctions like «AND», « $\mathrm{OR} »$. The link between the premise and the conclusion in the rules base is established through the conjunction "Then", which can be translated by the product or the minimum. The aggregation of the rules is generally done by the maximum or the sum.

\subsubsection{Defuzzification}

Treatment of inference rules provides a fuzzy value. The defuzzification step transforms the fuzzy set resulting from the aggregation of the rules into a precise numerical quantity of control to be applied to the process. In literature, there are several strategies to accomplish this operation, such as the average of maximas, the centre of the aeries and the centre of the maximas. The defuzzification method by the gravity center is the most used method in fuzzy commande. In fact, it intuitively provides the most representative value of the fuzzy set resulting from the rules aggregation [10]. It calculates the gravity center of the surface formed by the resulting membership function:

$$
y=\frac{\int_{a}^{b} z \cdot \mu_{A}(z) \cdot \mathrm{d} z}{\int_{a}^{b} \mu_{A}(z) \cdot \mathrm{d} z}
$$

\subsection{Mamdani Fuzzy Model}

The most commonly used inference methods are Max-Min (Mamdani), Max-Product and Sum-Product [11]. The 
"Mamdani" fuzzy inference method is based on a collection of rules. The Mamdani fuzzy model is one of the most popular algorithms. This method uses the concepts of fuzzy sets and fuzzy logic to translate an entirely unstructured set of linguistic heuristics into an algorithm. So, the fuzzy rule takes the following form:

$$
\text { If } X \text { is } A_{J} \text {, and } Y \text { is } B_{J} \text {, then } Z \text { is } C_{J}, J=1,2, \cdots, M
$$

Where $M$ is the total number of fuzzy rules, $X$ and $Y$ are input variables, and $Z$ is the output variable. $A, B$ and $C$ are fuzzy sets modeled by membership functions $\mu_{A_{J}}\left(x_{0}\right), \mu_{B_{J}}\left(y_{0}\right), \mu_{C_{J}}(z)$ respectively. The output of the fuzzy system involves several fuzzy rules. The fuzzy inference is the aggregating operation of fuzzy rules by the operator max application. For digital inputs $x_{0}$ and $y_{0}$, a fuzzy set of outputs denoted $F$ is generated according to the relationship:

$$
\mu_{F}(z)=\max _{J}\left[\min \left(\mu_{A_{J}}\left(x_{0}\right), \mu_{B_{J}}\left(y_{0}\right), \mu_{C_{J}}(z)\right)\right], \quad J=1,2, \cdots, M
$$

In the next section we apply the Mamdani model for performance evaluation of Production Systems.

\subsection{Fuzzy Logic Modeling}

\subsubsection{Fuzzification}

It converts input and output variables into fuzzy sets [Anis 2010]. As part of our study, we defined the following fuzzy variables:

\section{Linguistic variables:}

Three input variables (AR, PR, QR main indicators):

- AR: Availability rate

- PR: Performance rate

- QR: Quality rate

A single output variable (indicator).

- Efficiency of production systems.

\section{Linguistic values:}

- The input "TD" has been partitioned into 3 language values: available, not very available, unavailable.

- The input "TP" has been partitioned into 3 language values: performant, poor performing, and deficient.

- The input "TQ" has been partitioned into 3 language values: very good quality, good quality, poor quality.

- The language values for the output variable are: efficient, disturbing, very disturbing

- Discourse universe: the range of variation of input and output variables is the interval $(0 \%, 100 \%)$.

- Membership on the discourse universe functions: language values for the variables are represented by membership functions that are shown on Figure 5.

The choice of membership functions is usually made by the expert when creating variables. In our case, for triangular functions, we present the membership function for the variable 'Availability Rate'.

For the other membership functions, we give here only the discourse universe for each function.

- Performance rate: Performant [77.2 95 100], Poor Performing [53.44 71.25 83.12], Deficient [0 47.5 65.31].

- Quality rate: Very good quality [98-99-100], Good [96-98-99], Poor quality [0-96-97].

- Efficient production system: Efficiency [55.2 85 100], Disturbing [26 47 65], Very disturbing [0-25-39]. 


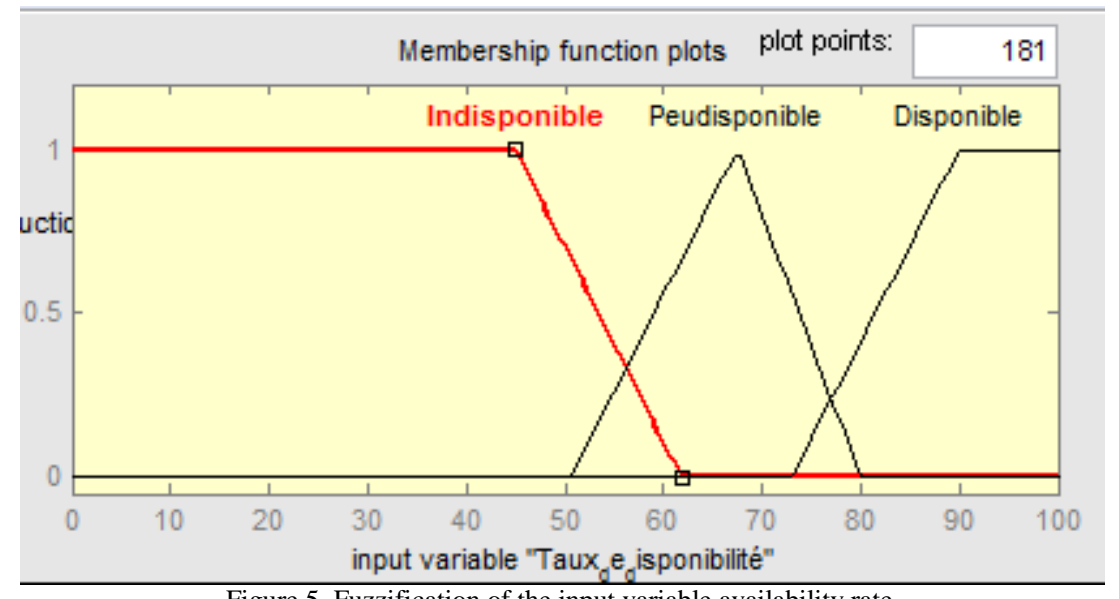

Figure 5. Fuzzification of the input variable availability rate

\subsubsection{The Inference Motor}

In this part, we must first define a set of inference rules from human knowledge. Here, a fuzzy rule is based on an approximate reasoning (the condition on the entries is true plus the recommended action for the outputs must be respected). It expresses the approximate knowledge of the conditional relationship between two or more variables [12].

Table 1 below summarizes the basis of the fuzzy rules. It is implemented through the expertise, knowledge and experience of the decision team members.

Table 1. Table of fuzzy rules

\begin{tabular}{|c|c|c|c|c|}
\hline \multirow{2}{*}{ Availability rate } & Performance rate & \multirow{2}{*}{ Performant } & \multirow{2}{*}{ Poor performing } & \multirow{2}{*}{ Deficient } \\
\hline & Quality rate & & & \\
\hline \multirow{3}{*}{ Available } & Very good quality & $\mathrm{E}$ & $\mathrm{E}$ & $\mathrm{D}$ \\
\hline & Good & $\mathrm{E}$ & $\mathrm{D}$ & $\mathrm{D}$ \\
\hline & Poor good & $\mathrm{E}$ & $\mathrm{D}$ & VD \\
\hline \multirow{3}{*}{ Not very available } & Very good quality & $\mathrm{E}$ & $\mathrm{D}$ & VD \\
\hline & Good & $\mathrm{D}$ & $\mathrm{D}$ & VD \\
\hline & Poor good & $\mathrm{D}$ & VD & VD \\
\hline \multirow{3}{*}{ Unavailable } & Very good quality & VD & VD & VD \\
\hline & Good & VD & VD & VD \\
\hline & Poor good & VD & VD & VD \\
\hline
\end{tabular}

\subsubsection{Défuzzification}

After having built the base of the rules, the last stage of defuzzification transforms the fuzzy set obtained by inference of the rules into a numerical value. As a rule, we associate this value with the output variable $y$, which is in the consequence of the rule base.

In our case, we used the center of gravity technique because of its popularity and their performances to present results that contain more subjective information.

\subsubsection{Simulation}

To illustrate the concept of our model, we consider an example programmed on Matlab:

We chose parameters [RA RP RQ] that equaled [80.05 72.07 98.14]. The simulation results are reported in Figure 6.

The proposed example uses two fuzzy rules (rule 10 and rule 11):

- Règle 10: If (availability rate is available) and (performance rate is Poor performing) and (quality rate is very good quality) so (efficient production system is Efficient)

- Rule 11: If (availability rate is available) and (performance rate is Poor performing) and (quality rate is good quality) so (efficient production system is Disturbing) 


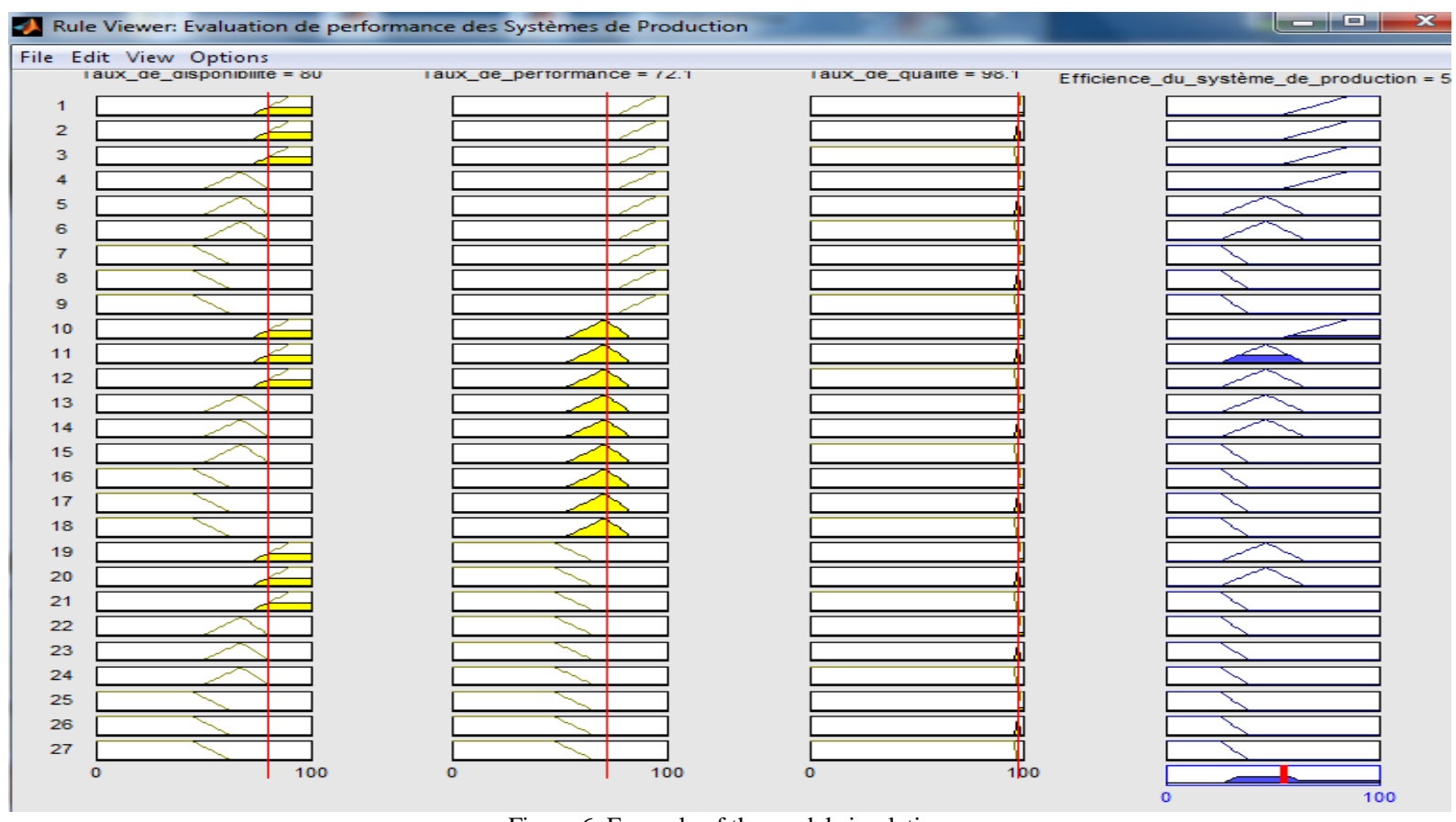

Figure 6. Example of the model simulation

Each rule uses the operator AND in the premise. The MIN functions used the Mamdani inference method. Output variables that match these rules are presented in Figure 7.

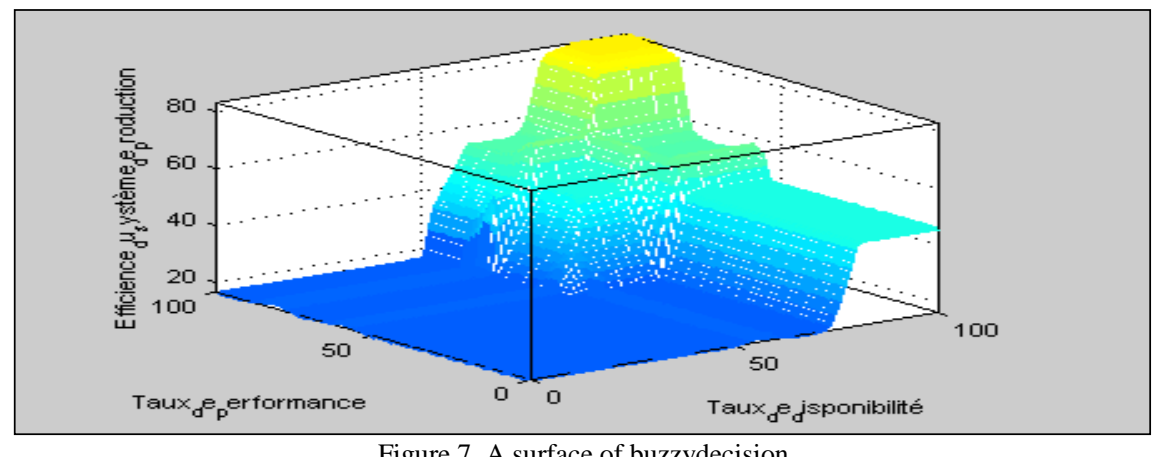

Figure 7. A surface of buzzydecision

In order to transform the fuzzy set obtained by inference rules, we need to highlight a digital step of defuzzification. In practice, we have a single variable of fuzzy output to be deffuzzyfied (efficiency of production systems) in order to obtain a numeric value. As shows Figure 8, the center of gravity $G$ represents the value numeric associated with the output variable and therefore, is worth $58 \%$, which is a more realistic value.

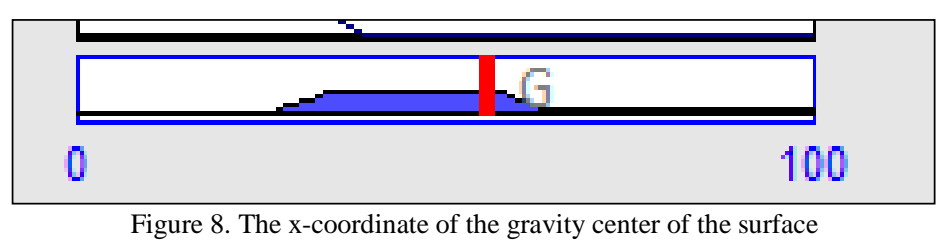

To validate our model on the objective of calculating overall equipment effectiveness OEE, Table 2 represents a comparison between the results obtained by the proposed new model and those obtained by the classical method:

The analysis of the data collected during month 1 shows that the results of the proposed model reached and OEE of $58 \%$ compared to $56 \%$ obtained by the conventional method. The relevance of the proposed model lies in its ability to help managers identify the influence of different major losses on OEE and also define important points for organizing resources towards improving the three rates of performance. 
Table 2. Comparison of the results between the new model proposed and the classic method

\begin{tabular}{|c|c|c|c|c|c|}
\hline \multirow{2}{*}{ Month } & \multicolumn{3}{|c|}{ Input } & \multirow{2}{*}{$\begin{array}{l}\text { Result obtained by the } \\
\text { classical method }\end{array}$} & \multirow{2}{*}{$\begin{array}{c}\text { Result obtained by } \\
\text { our model }\end{array}$} \\
\hline & RA & $\mathrm{RP}$ & RQ & & \\
\hline 1 & $80.05 \%$ & 72.07 & $98.14 \%$ & $56 \%$ & $58 \%$ \\
\hline
\end{tabular}

It is clear that in the classic method, the result is not accurate enough because it takes into account the output only without seeing the other entries and their interactions. Besides, it is not based on aspects generating losses in machines. Therefore, the values obtained can inaccurate and inconsistent with those expected. These can cause conflicts and nonquality within companies.

On the other hand, the proposed model makes it possible to fill all the inaccuracies of the classical method. Indeed, it is based on a method of decision support and takes into account the interactions between the three main constituents of the efficiency. Therefore, it provides a synthetic vision to guide operational decision makers (maintenance, production, etc.) to better control their resources and achieve their goals.

The results of the study show that the proposed model will be useful for businesses to initiate improvement activities to the good management of the performance, as well as the availability and the quality of their equipment. Indeed, it provides complete information on the various losses.

\section{Conclusions}

We proposed a model based on fuzzy logic to assess the efficiency of systems. The proposed model provides the most realistic and robust values and manufacturing output. We are exploring 3 other models:

- The first is a subsystem of the analysis of critical resources in the process followed and the factors that affect the performance of these resources.

- The second is a system for the identification of possible solutions for the inductor and the implementation of pilot actions intended to improve the level of performance attained.

- The third is an objective estimate of the OEE (Overall Equipment Effectiveness) target from the classic OEE.

\section{References}

1. K. Timothée, "Modélisation de la Propagation Des Fautes Dans Les Systèmes de Production," Thèse de Doctorat en Automatique Industrielle, Ecole Nationale Supérieure Polytechnique de Yaoundé, 30 Juin 2011

2. M. Bouziane, "Introduction du «Taux de Rendement Synthétique» (TRS) Parmi Les Indicateurs de Développement Durable," in Proceedings of Approche Technico-économique Pour Une Entreprise Durable, International Conférence on Energie and Sustainable Development, Novembre 2011

3. G. Habchi, "Modélisation Pour la Simulation D'un Système D'aide au Pilotage Industriel," Synthèse en Vue de L'habilitation à Diriger Des Recherches, Université de Savoie, 5 Décembre, 2011

4. A. Bounit and Y. Targhalline, "La Mise en Place D'un Modèle de Mesure de la Performance de L'usine BAHIA," Projet de Fin D'etudes en Génie Industriel, Ecole Nationale des Sciences Appliquées de Marrakech, Juin 2012

5. E. Irhirane, A. Bounit, and B. Dakkak, "Estimate of OEE (Overall Equipment Effectiveness) Objective from Classical OEE," International Journal of Performability Engineering, Vol. 13, No. 2, pp. 135-142, 2017

6. A. Bounit, E. Irhirane, N. Bourquia, and R. Benmoussa, "Design of a Fuzzy Model that Integrates Hygiene, Safety, and Environment Systems for the Assessment of the Overall Risk of Machines," Proceedings of the Institution of Mechanical Engineers, Part O: Journal of Risk and Reliability, Vol. 230, No. 4, pp. 378-390, 2016

7. Z. Yijun, "Contribution à L'évaluation et à la Modélisation du Bien-être Des Matériaux Textiles Habillement Par L'utilisation Des Techniques de Calcul Avancé," Thèse de Doctorat en Automatique, Génie Informatique, Traitement du Signal et Des Images, Université de Lile, Décembre 2010

8. L. A. Zadeh, "Fuzzy sets," Information and Control, Vol. 8, No. 3, pp. 338-353, 1965

9. E. Irhirane, A. Bounit, B. Dakkak, R. Benmoussa, and N. Bourquia, "New Approach Integrating the Health, Safety, and Environment Systems for the Maintenance Function in Industries," Proceedings of the Institution of Mechanical Engineers, Part E: Journal of Process Mechanical Engineering, 2018

10. P. Ponce-Cruz and F. D. Ramirez-Figueroa, "Intelligent Control Systems with LabVIEWTM 9," Springer, 2010

11. O. Y. Abul-Haggag and W. Barakat, "Application of Fuzzy Logic for Risk Assessment using Risk Matrix," International Journal of Emerging Technology and Advanced Engineering, pp. 49 -53, 2013

12. M. Anis, "Contribution à la Gestion des Perturbations dans les Systèmes Manufacturiers à Contraintes de Temps," Thèse de Doctorat en Automatique et Informatique Industrielle, Ecole Nationale D'ingénieurs de Tunis, Juillet 2010 